\title{
The communication Between Diabetes and Alzheimer's Disease: a study on diabetic patients referring to health centers in three cities of Khuzestan province
}

\author{
Mostafa Madmoli ${ }^{1 *}$, Mohammad Madmoli², Mahboobeh Khodadadi' ${ }^{3}$, Yaghoob Madmoli ${ }^{4}$ \\ ${ }^{1}$ Emergency Medical Technician, Dezful University of Medical Sciences, Dezful, Iran* \\ ${ }^{2}$ Student Research Committee Shoushtar faculty of Medical Sciences, Shoushtar, Iran. \\ ${ }^{3}$ Nursing Student, Student Research Committee, Dezful University of Medical Sciences, Dezful, Iran. \\ ${ }^{4}$ Msc Student of nursing, Student Research Committee, Ahvaz Jundishapur University of Medical Sciences, Ahvaz, \\ Iran.
}

\begin{abstract}
Introduction: Epidemiological studies suggest convincing evidence for a meaningful relationship between type 2 diabetes and dementia. It also shows that type 2 diabetes is a major cause of Alzheimer's disease. Given the Iranian population's profile of about 31 million middle-aged people, in the next two decades, older people will form a large population. On the other hand, the increase in Alzheimer's in the elderly is due to the prevalence of this disorder and the adverse effects and adverse effects in the next two decades. And so far, quantitative research has been conducted to investigate the risk of Alzheimer's disease in diabetic patients in Khuzestan province. Therefore, this study titled "The communication Between Diabetes and Alzheimer's Disease: study on diabetic patients referring to health centers in three cities of Khuzestan province" was done.
\end{abstract}

Materials and Methods: This retrospective cross-sectional descriptive study was conducted on diabetic patients hospitalized in Shoushtar, Behbahan, and Abadan, between 2015 to 2017. The files of these patients who were diagnosed with diabetes and referred to medical centers in the mentioned cities that were extracted from medical records of city hospitals and entered the study. Data were then entered into SPSS software version 20. Data were analyzed using descriptive statistics, analytical tests and the significance level of $\mathrm{P}<0.05$.

Results: In this study, the mean age of patients was $57.00 \pm 46.23$ years. A statistically significant relationship was found between diabetes and those with Alzheimer's disease $(p=0.006)$. However, there was no significant relationship between diabetes and those with a history of cardiovascular disease $(p=0.09)$. There was no significant relationship between education and those with Alzheimer's disease (0.06). But a statistically significant relationship was found between jobs with those with Alzheimer's disease (0.003).

Conclusion: In this study, there was a significant relationship between diabetes and those with Alzheimer's disease. Therefore, this study showed the risk of Alzheimer's disease in diabetic patients in the three mentioned cities. More epidemiological and clinical research is needed to investigate the relationship between these two diseases in a wider and larger volume.

Keywords: Diabetes, Diabetic Patients, Risk Factor, Alzheimer's Disease.

\section{Address For Correspondence}

Mostafa Madmoli, Emergency Medical Technician, Dezful University of Medical Sciences, Dezful, Iran.

E-mail: mostafamadmoli10@yahoo.com

Received: 29-03-2019

Received: 10-04-2019

Accepted: 24-04-2019

International Research in Medical and Health Sciences | Vol 2|Issue 2| March-April 2019

Page 8 


\section{Introduction:}

Diabetes is a major cause of morbidity and mortality in the industrialized and developing world. This disease is a chronic, metabolic disease characterized by increased levels of glucose in the blood and carbohydrate metabolism, protein, and lipids (1-7). In 2014, the global prevalence of diabetes among adults older than 18 years of age was estimated at $9 \%$. The prevalence of this disease in Iran is more than $14 \%$ or more in the population of women, according to statistics released by the health ministry's health department in a population over the age of 30 . People with diabetes who have a BMI greater than a "normal" level are at risk of secondary complications of diabetes, one of which is the complication of cancer (8-18).

The disease with its complications is not reversible in many cases. In general, these complications can cause many illnesses. Most studies have shown that patients with diabetes who are less self-healing have more complications (19-24).

Complications of diabetes are very common among patients with this condition and we are going to examine a few cases. Among diabetic patients, depression is one of the most common psychiatric disorders $(25,26)$. Depression and occupational stress daily can cause some disorders in people's mental and physical health. Job stress is a physical and emotional response that can lead to illness and injury (27-30). Diabetes prevalent among many diseases, one of which is thalassemia (31). Thalassemia is one of the most common abnormalities in the blood, which leads to a sharp decrease in the quality of life in people with this condition $(32,34)$.

Another complication of diabetes is the development of Alzheimer's disease. Alzheimer's disease is a chronic progressive and debilitating brain disorder that with profound effects on memory, intelligence and self-care. Alzheimer's causes include progressive deficiency in brain glucose, energy metabolism, cellular skeletal system, myelin retention, and neural flexion $(35,36)$. Epidemiologic studies suggest convincing evidence for a meaningful relationship between type 2 diabetes and dementia. And it also shows that type 2 diabetes is a major cause of Alzheimer's disease (37-39). However, these findings are no different and in a long-term survey, researchers found that although borderline diabetes significantly increased the risk of diabetes, dementia or Alzheimer's, the effects of the risk are not independent and dependent (40). This means that insulin resistance, the ability to respond to stimulation of insulin, varies in different organs (41).

Given the Iranian population's profile of about 31 million middle-aged people, in the next two decades, older people will form a large population. On the other hand, the increase in Alzheimer's in the elderly is due to the prevalence of this disorder and the adverse effects and adverse effects in the next two decades $(42,43)$. And so far, quantitative research has been conducted to investigate the risk of Alzheimer's disease in diabetic patients in Khuzestan province. Therefore, this study titled "The communication Between Diabetes and Alzheimer's Disease: study on diabetic patients referring to health centers in three cities of Khuzestan province" was done.

Materials and Methods: Information required for this study is a retrospective crosssectional analytical descriptive study which used to review patient files during the years 2015 to 2017 in the medical records section the hospitals of the Shoushtar, Behbahan, and Abadan city was extracted. The inclusion criteria included all diabetic patients in each age group and sex that they were diagnosed with the disease, from cases that had a medical diagnosis other than the disease, and cases that were incompletely filled were not used and were excluded.

The study included a survey of 1855 diabetic patients admitted to the hospitals in the abovementioned city. The patients who were diagnosed with diabetes and referred to treatment centers in the city from 2015 to 2017 were included in the study.

In order to study the records and collect data, a written Letter of Introduction from the Deputy of Education and Research of the Medical Sciences Universities of the mentioned city was taken. 
Then, the records of patients referring to health centers in the archives department were used. The required information was collected through a researcher checklist from the records. All examined in this study included demographic, clinical laboratories, such as gender, age, marital status, ethnicity, occupation, socioeconomic status, education level, having or not having a history of diabetes, Cardiovascular disease and Alzheimer's disease and family history of diabetes. Data were then entered into SPSS version 20 software. Data were analyzed by descriptive statistics including enumerated tables, mean, standard deviation and variance, and analytical tests including Chi-square and Chi-square Pearson, T-test and at the significant level of $\mathrm{P}$ $<0.05$.

Results: The study included 1855 individuals with diabetes mellitus with an average age of

Figure 1: The frequency of some risk factors and complications of diabetes in diabetic patients

Frequency of some risk factor and complications of diabetes

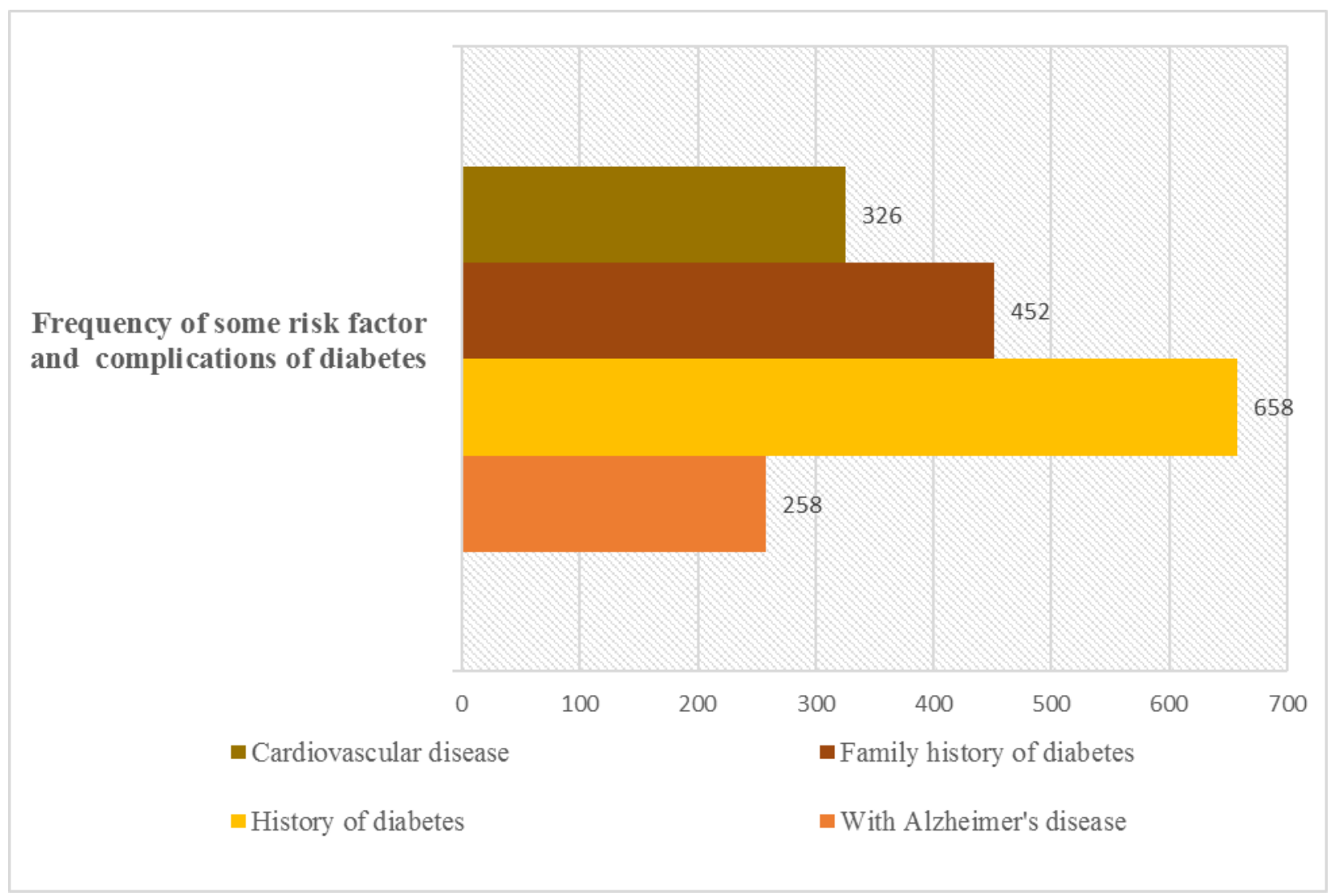

International Research in Medical and Health Sciences | Vol 2| Issue 2| March-April 2019
$57.00 \pm 46.23$ years. In terms of the job, the highest percentage of jobless was $37 \%$. In this study, $42.6 \%$ of graduates had the highest academic qualifications.

In this study, $13.9 \%$ of those with diabetes also had Alzheimer's disease. Also, 35.4\% of people with a history of diabetes, $24.3 \%$ of family history of diabetes, and $17.5 \%$ had cardiovascular disease. There was a significant relationship between diabetes and those with Alzheimer's disease $(\mathrm{p}=$ 0.006). However, there was no significant relationship between diabetes and those with a history of cardiovascular disease $(p=0.09)$. Figure 1

There was no significant relationship between education and those with Alzheimer's disease (0.06). But a statistically significant relationship was found between jobs with those with Alzheimer's disease (0.003). 
Discussion: Diabetes is a major cause of morbidity and mortality in the industrialized and developing world. This disease is a chronic, metabolic disease characterized by increased levels of glucose in the blood and carbohydrate metabolism, protein, and lipids (1-7). Epidemiological studies suggest convincing evidence for a meaningful relationship between type 2 diabetes and dementia. It also shows that type 2 diabetes is a major cause of Alzheimer's disease. Given the Iranian population's profile of about 31 million middle-aged people, in the next two decades, older people will form a large population. On the other hand, the increase in Alzheimer's in the elderly is due to the prevalence of this disorder and the adverse effects and adverse effects in the next two decades. And so far, quantitative research has been conducted to investigate the risk of Alzheimer's disease in diabetic patients in Khuzestan province. Therefore, this study titled "The communication Between Diabetes and Alzheimer's Disease: study on diabetic patients referring to health centers in three cities of Khuzestan province" was done.

In one study, the prevalence of Alzheimer's disease was calculated. Of those over $65,10.3 \%$ had Alzheimer's disease. 18.7 percent of people aged 75-84 and 2.47 percent of those over 85 years old (44). Age is the largest risk factor for Alzheimer's disease and the prevalence of this disease increases with age. Many epigenetic changes occur with natural aging. These changes are seen in Alzheimer's disease. The main cause of this disease is the destruction of neuronal cells in the brain, leading to the emergence of aging plaques that ultimately lead to the death of neurons (45).

In this study, $17.5 \%$ of diabetic patients had cardiovascular disease. In another study, the prevalence of heart problems in diabetic patients was $39.7 \%$ and was not consistent with the study, which can be due to different nutrition, low aerobic exercise, and so on (3). Diabetes has always been a risk factor for cardiovascular disease. For example, a study was conducted to investigate four major cardiovascular risk factors (hypertension, diabetes, cigarette, and dyslipidemia), and over 2,000 patients were examined, most of them having at least one of four risk factors (46). Other study results also found that $6.84 \%$ of women and $6.80 \%$ of men had at least one of the four major cardiovascular risk factors (hypertension, diabetes, cigarette, and dyslipidemia) (47).

In this study, $13.9 \%$ of those with diabetes also had Alzheimer's disease. There was also a significant relationship between diabetes and those with Alzheimer's disease. The results of the study by Madmoli et al. (4) showed that there was no significant relationship between Alzheimer's disease and diabetes. But there was a significant relationship between insulin consumption and Alzheimer's disease, which was not consistent with this study. The reason for this inconsistency can be due to differences in lifestyle in the two studies, dietary differences, and so on.

A study of some studies has shown that chronic consumption of high-fat diets and diabetes is one of the factors that reduces cognitive function and a type of dementia. In a study using magnetic resonance imaging, diabetic patients showed decreased levels of the hippocampus and decreased cognitive speed compared with older adults (48).

The results of the study showed that the animals undergoing type 2 diabetes-induced memory deficiency in comparison with non-diabetic SAMP8 mice. The authors also showed that these animals contained beta-amyloid proteins in the brain and hyperphosphorylated Tau proteins in the hippocampus, indicating similar changes to Alzheimer's disease (49).

In one study, over $80 \%$ of Alzheimer's cases had Type II diabetes or IFG (Impaired Fasting Glucose) (50). This study also reveals the link between diabetes and Alzheimer's.

Conclusion: In this study, there was a significant relationship between diabetes and those with Alzheimer's disease. Therefore, this study showed the risk of Alzheimer's disease in diabetic patients in the three mentioned cities. More epidemiological and clinical research is needed to investigate the relationship between these two diseases in a wider and larger volume. 
Acknowledgment: The authors of this article are grateful to all those who have collaborated with us in this article.

Conflict of interest: There are no conflicts of interest in this study.

\section{References:}

1. Madmoli M, Kord Z, Bandani A, Sedighi N, Rezaei Shandiz M, Darabiyan P, AfsharNia A. Epidemiological and clinical study of patients with Alzheimer's in Five Cities of Khuzestan Province in 2016-2018. Medical Science, 2019; 23(95), 1-5

2. Moslemirad M, Madmoli M, Madmoli Y, Niksefat M. Prevalence of type 1 and type 2 diabetes and its related factors in diabetic patients hospitalized in Khatamol-Anbia hospital in Shoushtar, 2014-15: A retrospective study. Journal of Research in Medical and Dental Science. 2018;6(3):421-6

3. Madmoli M, Eilami O, Rezaie K, Aliabad MA, Moslemirad M. Diabetes and the risk of suffering cardiovascular Diseases: A two-year retrospective study. International Journal of Ecosystems and Ecology Science (IJEES). 2018 Jun;8(3): 649-56.

4. Raisifar Z, Afshar Nia A, Madmoli M, Madmoli Y. The Relationship Between Using Insulin and Suffering Alzheimer's Disease in Patients with Diabetes: A TwoYear Study. International Journal of Ecosystems and Ecology Science (IJEES). 2018 June; 8 (3): 623-28.

5. Raisifar Z, Afshar Nia A, Maghamesi Moarrefi H, Madmoli M. Evaluation of Gi Bleeding Prevalence and Its Related Factors in Diabetic Patients Hospitalized in KHatam-ol-Anbia Hospital During 2015-16: A Retrospective Study. International Journal of Ecosystems and Ecology Science (IJEES). 2018 June; 8 (3): 609-14.

6. Mashali H, Toleideh F, Rahmani R, Darabiyan P, Madmoli M. The predictive role of Hyperlipidemia in the incidence of ACS in patients referring to Shahidzadeh
Hospital in Behbahan in 2016 -2017. Medical Science, 2018; 22(94), 566-570

7. Madmoli M, Modheji Y, Rafi A, Feyzi R, Darabiyan P, AfsharNia A. Diabetes and its predictive role in the incidence of Alzheimer's disease. Medical Science, 2019; 23(95), 30-34

8. Madmoli $M$, Abbaszade Aliabad $M$, Madmoli M, Khodadadi M, Papi Ahmadi F. The Effect of Some Factors on Self-Care in Diabetic Patients: A Systematic Review. Journal of Genetics and Genetic Engineering. 2019; 3(1): 21-25

9. Madmoli M. A Systematic Review Study on the Changer Factors of the Quality of life in Cancer Patients. Int. Res. Med. Health Sci., 2019; 2(1):8-15.

10. Madmoli M. A systematic Review Study on the Results of Empowerment-Based Interventions in Diabetic Patients. Int. Res. Med. Health Sci., 2019; 2(1):1-7.

11. Madmoli M, Fallah bagher shaidaei $M$, Rohani A, Darabiyan P, Mobarez F. The correlation between alcohol consumption and reducing the age of cancer incidence in patients with this disease. Medical Science, 2019, 23(95), 48-53

12. Madmoli M, Mahmoudi Dehcheshmeh Z, Rafi A, Zahra Kord, Fariba Mobarez, Pouriya Darabiyan. The rate of some complications and risk factors of diabetes in diabetic patients: Study on cases of 3218 diabetic patients. Medical Science, 2019; 23(95), 63-68

13. Mostafa Madmoli, Mehran Yarbig, Negin Sedighi, Pouriya Darabiyan, Fariba Mobarez. Communication between body mass index and the risk of obesity-related cancer: A 5-year study on patients with cancer. Medical Science, 2019; 23(95), 6974

14. Madmoli M. Clinical and Laboratory Finding in Children with Leukemia: a Systematic Review. International Journal of Research Studies in Science, Engineering, and Technology, vol. 5, no. 10, pp .2018; 1-6

15. Madmoli M. Evaluation of Chemotherapy Complications in Patients with Cancer: A Systematic Review. International Journal of Research Studies in Science, 
Engineering, and Technology, vol. 5, no. 12, 2018; 59-64.

16. Madmoli M, Madmoli $Y$, Khodadadi M, Samsamipour M. Study of Some Effective Treatments for Accelerating Diabetic Foot Ulcer Healing: A Systematic Review. International Journal of Research Studies in Science, Engineering, and Technology. 6(2), 2019; 34-39

17. Madmoli M Rostami F, Mirsami Yazdi N, Mosavi A, Baraz Sh. Evaluation of Prevalence of Diabetic Foot Ulcer and Its Related Factors in Diabetic Patients Admitted to KHatam-ol-Anbia Hospital in Shoushtar During 2015-2016: A Retrospective Study. International Journal of Ecosystems and Ecology Science (IJEES). 2018 June; 8 (3): 545-52.

18. Rostami F, Madmoli M, Mirsami Yazdi N, Baraz Sh. Evaluation of The Prevalence of Lower Limb Amputation and Its Related Factors in Diabetic Patients Admitted to KHatam-ol-Anbia Hospital in Shoushtar During The 2015-2016: A Retrospective Study. International Journal of Ecosystems and Ecology Science (IJEES). 2018 June; 8 (3): 553-60.

19. Madmoli M, Madmoli $Y$, Khodadadi $M$, Samsamipour M. Factors Affecting the Level of Glycosylated Hemoglobin in Patients with Diabetes: A Systematic Review. Annals of Microbiology and Infectious Diseases 2(1), 2019; 43-47.

20. Madmoli, M. A Systematic Review Study on the Communication between Diabetes and Cancer: The Serious Risk of Cancer in Diabetic Patients. International Research in Medical and Health Science. 2019; 2(2), 1-7.

21. Madmoli M. Quality of Life in Patients with Cancer and Some Factors Affecting it: A Systematic Review. International Journal of Research Studies in Science, Engineering, and Technology. 6(1), 2019; 1-7

22. Madmoli M, Madmoli Y, Khodadadi M, Samsamipour M. Study of Some Effective Treatments for Accelerating Diabetic Foot Ulcer Healing: A Systematic Review.
International Journal of Research Studies in Science, Engineering and Technology, 6(2), 2019; 34-39

23. Madmoli M, Madmoli Y, Khodadadi M, Samsamipour M. Factors Affecting the Level of Glycosylated Hemoglobin in Patients with Diabetes: A Systematic Review. Annals of Microbiology and Infectious Diseases 2(1), 2019; 43-47.

24. Madmoli M, Madmoli Y, Khodadadi M, Samsamipour M. Some Factors Affecting Quality of Life in Patients with Diabetes: A systematic Review", Annals of Microbiology and Infectious Diseases, 2(1), 2019; 26-30.

25. Madmoli M, Madmoli Y, Bigdeli Shamloo MB, Etebari A, Mahmoodi Kouhi A, Azami M. The Relationship Between Depression and Religiousness in Female High School Students of Masjed Soleyman in 2015. Journal of Pediatric Nursing. 2017 Jun 15;3(4):15-22.

26. Madmoli Y, Madmoli M, Qashqaei Nezhad N, Bosak S. Prevalence of depression and associated factors in adolescents of Masjed-Soleyman. Iranian Journal of Pediatric Nursing. 2016.

27. Gheisari Z, Beiranvand R, Karimi A, Ghalavandi S, Soleymani A, Madmoli M, Bavarsad AH. Relationship between Occupational Stress and Cardiovascular Risk Factors Determination: A Casecontrol Study. Journal of Research in Medical and Dental Science. 2018 May 17;6(3):287-93.

28. Madmoli M, Nikpay S. An Investigation of the Relationship between Spiritual Health and Depression, Anxiety, and Stress among Students of Ilam University of Medical Sciences. Journal of Research in Medical and Dental Science. 2018 May 17;6(3):294-300.

29. Adavi A, Hamid N, Attari Y, Madmoli Y, Madmoli M. Study of the Effect of Problem-Solving Skills Training on Creativity and Assertiveness Among High School Students. Iranian Journal of Nursing Research. 2016 Dec 15;11(5):4855. 
30. Roughani A, Madmoli M, Raisifar Z, Kikhavani S, Yasemi M, Azami M, Sharifi Z. The prevalence of behavioral disorders and its related factors in elementary school children in Ilam City in 20112012. Indian Journal of Forensic Medicine \& Toxicology. 2018;12(4):165-9

31. Madmoli M. A systematic Review Study on the Results of Empowerment-Based Interventions in Diabetic Patients. Int. Res. Med. Health Sci., 2019; 2(1):1-7.

32. Madmoli Y, Akhaghi Dezfuli SM, Beiranvand R, Saberi Pour B, Azami M, Madmoli M. An epidemiological and clinical survey of patients with $\beta$ thalassemia in dezful in 2015. Iranian Journal of Epidemiology. 2017;13(2):14552.

33. Madmoli Y, Akhaghi Dezfuli SM, Adavi A, Maraaghi E, Heidari Soureshjani R, Madmoli M. The Effect of Orem Self-Care on Mental Health of Patients with Thalassemia Major. Journal of Clinical Nursing and Midwifery. 2018 Jul 1;7(2):108-15.

34. Madmoli M, Madmoli Y, Rahmati P, Adavi A, Yousefi N, Gheisari Z, Abbaszade Aliabad M. Quality of Life and Some Related Factors in Patients with Beta Thalassemia Major in Southwest Iran. Journal of Client-centered Nursing Care (JCCNC. 2017;3(2).

35. Suzanne M. Contributions of brain insulin resistance and deficiency in amyloidrelated neurodegeneration in Alzheimer's disease. Drugs. 2012;72(1):49-66.

36. de la Monte SM, Longato L, Tong M, Wands JR. Insulin resistance and neurodegeneration: roles of obesity, type 2 diabetes mellitus, and non-alcoholic steatohepatitis. Current opinion in investigational drugs (London, England: 2000). 2009;10(10):1049.

37. Pasquier F, Boulogne A, Leys D, Fontaine P. Diabetes mellitus and dementia. Diabetes Metab. 2006;32(5 Pt 1):403-14.
38. Haan MN, Wallace R. Can dementia be prevented? Brain aging in a populationbased context. Annu Rev Public Health. 2004; 25:1-24.

39. Whitmer RA. Type 2 diabetes and risk of cognitive impairment and dementia. Curr Neurol Neurosci Rep. 2007;7(5):373-80.

40. Xu W, Qiu C, Winblad B, Fratiglioni L. The effect of borderline diabetes on the risk of dementia and Alzheimer's disease. Diabetes. 2007;56(1):211-6.

41. Whitmer RA, Gunderson EP, Quesenberry CP Jr, Zhou J, Yaffe K. Body mass index in midlife and risk of Alzheimer disease and vascular dementia. Curr Alzheimer Res. 2007;4(2):103-9.

42. Mahdavi B, FALLAHI KM, Mohammadi F, Hosseini M. The effect of group spiritual care on quality of life in family caregivers of elders with Alzheimer's disease. 2015.

43. Bastani F, Ghasemi E, Negarandeh R, Haghani H. General self-efficacy among family's female caregiver of elderly with Alzheimer's disease. Journal of Hayat. 2012;18(2):27-37.

44. Wood IC. The contribution and therapeutic potential of epigenetic modifications in Alzheimer's disease. Frontiers in Neuroscience. 2018; 12:649.

45. Evans DA, Funkenstein HH, Albert MS, Scherr PA, Cook NR, Chown MJ, Hebert LE, Hennekens $\mathrm{CH}$, Taylor JO. Prevalence of Alzheimer's disease in a community population of older persons: higher than previously reported. Jama. 1989 Nov 10;262(18):2551-6.

46. van Wyk JT. Identification of the four conventional cardiovascular disease risk factors by Dutch general practitioners.Chest 2005;128:25212527.

47. Khot UN, Khot MB, Bajzer CT, Sapp SK, Ohman EM, Brener SJ, Ellis SG, Lincoff AM, Topol EJ. Prevalence of conventional risk factors in patients with coronary heart disease. JAMA. 2003; 290:898-904.

48. Bruehl H, Wolf OT, Sweat V, et al. Modifiers of cognitive function and brain structure in middle-aged and elderly 
individuals with type 2 diabetes mellitus. Brain Res. 2009; 1280:186-94.

49. Mehla J, Chauhan BC, Chauhan NB. Experimental induction of type 2 diabetes in aging-accelerated mice triggered Alzheimer-like pathology and memory deficits. J Alzheimers Dis. 2014; 39:14562.
50. Janson J, Laedtke T, Parisi JE, O'Brien P, Petersen RC, Butler PC. Increased risk of type 2 diabetes in Alzheimer disease. Diabetes. 2004 Feb 1;53(2):474-81. 